\title{
Noggin Expands Neural Stem Cells in the Adult Hippocampus
}

\author{
Michael A. Bonaguidi, ${ }^{1,2,3 \star}$ Chian-Yu Peng, ${ }^{\star}{ }^{\star}$ Tammy McGuire, ${ }^{1}$ Gustave Falciglia, ${ }^{1,4}$ Kevin T. Gobeske, ${ }^{1}$ \\ Catherine Czeisler, ${ }^{1,5}$ and John A. Kessler ${ }^{1}$ \\ ${ }^{1}$ Davee Department of Neurology, Northwestern University's Feinberg School of Medicine, Chicago, Illinois 60611, ${ }^{2}$ Institute for Cell Engineering and \\ ${ }^{3}$ Department of Neurology, Johns Hopkins University School of Medicine, Baltimore, Maryland 21205, ${ }^{4}$ Department of Pediatrics, University of Chicago, \\ Chicago, Illinois 60637, and ${ }^{5}$ Cardiovascular Research Institute, University of California, San Francisco, San Francisco, California 94158
}

New neurons are added to the adult hippocampus throughout life and contribute to cognitive functions, including learning and memory. It remains unclear whether ongoing neurogenesis arises from self-renewing neural stem cells (NSCs) or from multipotential progenitor cells that cannot self-renew in the hippocampus. This is primarily based on observations that neural precursors derived from the subventricular zone (SVZ) can be passaged long term, whereas hippocampal subgranular zone (SGZ) precursors are rapidly depleted by passaging. We demonstrate here that high levels of bone morphogenetic protein (BMP) signaling occur in hippocampal but not SVZ precursors in vitro, and blocking BMP signaling with Noggin is sufficient to foster hippocampal cell self-renewal, proliferation, and multipotentiality using single-cell clonal analysis. Moreover, NSC maintenance requires continual Noggin exposure, which implicates BMPs as crucial regulators of NSC aging. In vivo, Noggin is expressed in the adult dentate gyrus and limits BMP signaling in proliferative cells of the SGZ. Transgenic Noggin overexpression in the SGZ increases multiple precursor cell populations but proportionally increases the glial fibrillary acidic protein-positive cell population at the expense of other precursors, suggesting that Noggin acts on NSCs in vivo. To confirm this, we used a dual thymidine analog paradigm to repeatedly label slowly dividing cells over a long duration. We find that small populations of label-retaining cells exist in the SGZ and that Noggin overexpression increases their numbers. Thus, we propose that the adult hippocampus contains a population of NSCs, which can be expanded both in vitro and in vivo by blocking BMP signaling.

Key words: hippocampus; progenitor; bone morphogenetic protein; neurogenesis; development; aging

\section{Introduction}

Neurogenesis persists throughout life in the adult brain in the subgranular zone (SGZ) of the hippocampal dentate gyrus (DG) as well as in the subventricular zone (SVZ) adjacent to the lateral ventricle (Altman and Das, 1965; Kaplan and Hinds, 1977). Neuron turnover in the granule cell layer (GCL) of the adult DG maintains normal hippocampal function, is correlated with hippocampus-dependent learning, and may be involved in depression and epilepsy (Parent et al., 1997; Gould et al., 1999; Shors et al., 2001; van Praag et al., 2002; Santarelli et al., 2003; Raber et al., 2004). The SVZ contains self-renewing neural stem cells (NSCs) (Reynolds and Weiss, 1992; Morshead et al., 1994), and early studies hypothesized that self-renewing NSCs are also present in the adult hippocampus (Palmer et al., 1997). However, more recent studies have concluded that the adult hippocampus contains neurogenic progenitor cells (NPCs) but not stem cells, because hippocampal precursors appear to lack the ability to self-

\footnotetext{
Received July 21, 2007; revised July 7, 2008; accepted July 27, 2008.

This work was supported by National Institutes of Health Grants NS20013 and NS20778 to J.A.K. We thank Vibhu Sahni and Abhishek Mukhopadhyay for technical assistance and manuscript discussion.

${ }^{*}$ M.A.B. and C.-Y.P. contributed equally to this work.

Correspondence should be addressed to Michael A. Bonaguidi, 733 North Broadway, \#706, Baltimore, MD 21205. E-mail: mbonagu1@jhmi.edu.

DOI:10.1523/JNEUROSCI.3314-07.2008

Copyright $\odot 2008$ Society for Neuroscience $\quad$ 0270-6474/08/289194-11\$15.00/0
}

renew (Seaberg and van der Kooy, 2002; Bull and Bartlett, 2005). Meanwhile, the adjacent posterior lateral ventricle contains NSCs, and it has been proposed that these are the cells that maintain continual neurogenesis in the SGZ (Bull and Bartlett, 2005).

Neural stem and progenitor cells reside in microenvironmental niches that are modified by environmental stimuli to regulate multiple aspects of precursor development (Hagg, 2005; Ma et al., 2005). For example, bone morphogenetic proteins (BMPs) are negative regulators of the adult SVZ and juvenile SGZ neurogenic niches and limit precursor number, proliferation, and neuronal fate specification (Lim et al., 2000; Bonaguidi et al., 2005). BMPs exert their biological effects by binding to type I (BMPRIa and BMPRIb) and type II (BMPRII) receptor subunits that are organized with minor modifications of the prototypical TGF $\beta$ subclass of serine-threonine kinase receptors (for review, see Derynck and Zhang, 2003). Binding of BMPs to their receptors leads to phosphorylation of SMAD1, SMAD5, and SMAD8 (SMAD1/5/ 8 ), which translocate to the nucleus and activate transcription. BMP actions are regulated in vivo by proteins such as Noggin, follistatin, chordin, and neurogenesin that antagonize BMP signaling by directly binding BMPs and blocking ligand activity.

In previous studies, we found that neural precursor cells endogenously produce BMPs, which promote neural precursor exit from cell cycle and loss of precursor characteristics (Bonaguidi et al., 2005). This suggested that previous attempts to demonstrate 
the presence of a hippocampal stem cell in vitro might have been confounded by the endogenous production of BMPs. Here, we demonstrate that hippocampal cells cultured in the presence of the BMP inhibitor Noggin are able to self-renew and to generate neurons. We further establish in vivo that the adult SGZ contains a cell population with neural stem cell characteristics and that BMP signaling regulates their numbers within the neurogenic niche.

\section{Materials and Methods}

Animals. The generation of the neuron-specific enolase (NSE)-Noggin and NSE-BMP4 transgenic mice has been described previously (Gomes et al., 2003; Guha et al., 2004). FVB and C57BL/6 male mice were purchased from The Jackson Laboratory. Adult mice were used between 2 and 4 months of age. All mice were housed in a facility with a 14/10 h light/dark cycle and allowed access to food and water ad libitum. Experiments were conducted according to protocols approved by Institutional Animal Care and Use Committee and Northwestern Center for Comparative Medicine.

Thymidine analogs. Bromodeoxyuridine (BrdU) (Sigma) was given via four intraperitoneal injections of $50 \mathrm{mg} / \mathrm{kg}$ daily every $3 \mathrm{~h}$ for 3 consecutive days followed by cardiac perfusion $3 \mathrm{~h}$ after the final injection (Cao et al., 2004). In a separate set of experiments, $1.15 \mathrm{mg} / \mathrm{ml} 5$-chloro- $2^{\prime}$ -

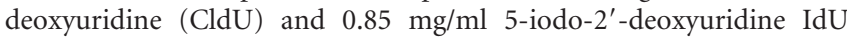
(Sigma) were provided in drinking water with $2.5 \%$ sucrose. IdU was administered for 14 consecutive days, followed by water for $7 \mathrm{~d}$, CldU for $14 \mathrm{~d}$, and water again for $7 \mathrm{~d}$, and the animals were killed (Bauer and Patterson, 2006). Wild-type and transgenic animals consumed similar amounts of drinking water. For 5-ethynyl-2'-deoxyuridine (EdU) (Invitrogen) labeling of hippocampal neurospheres, Noggin-induced neurospheres were cultured with or without Noggin for $5 \mathrm{~d}$ before enzymatically dissociated into single cells. At $24 \mathrm{~h}$ later, cells were incubated with EdU for $4 \mathrm{~h}$ and then processed for EdU detection according to the protocol of the manufacturer (Click-IT Flow Cytometry Assay kit; Invitrogen). After staining, cells were analyzed by flow cytometry based on 488 [EdU-positive $\left(\mathrm{EdU}^{+}\right)$] and 633 (propidium iodide ${ }^{+}$) fluorescence positivity, and percentage of labeled cells were quantified (Cyan ADB; DakoCytomation).

Telomerase real-time PCR. Total RNA was collected using the RNAqueous-4PCR kit (Ambion) from passage 3-4 Noggin-induced hippocampal neurospheres after being cultured with or without Noggin for $5 \mathrm{~d}$. A total of $1 \mu \mathrm{g}$ of RNA was used for generating cDNA using the Thermoscript reverse transcriptase and oligo-dT primers (Invitrogen), and $2 \mu \mathrm{l}$ of cDNA was used per PCR reaction. PCR was performed with the SybrGreen master mix (Applied Biosystems) and Realplex ${ }^{2}$ Mastercycler (Eppendorf) using the following cycling parameters: $95^{\circ} \mathrm{C}, 15 \mathrm{~s}$; $58^{\circ} \mathrm{C}, 60 \mathrm{~s}$ for 40 cycles. Primers against the mouse telomerase real-time (TERT) (5' -GAC ATG GAG AAC AAG CTG TTT GC-3'; 5' -ACA GGG AAG TTC ACC ACT GTC-3') were designed according to published sequences (Cai et al., 2002) and purchased from Integrated DNA Technologies. PCR product was analyzed on a $2.0 \%$ agarose gel and imaged with Gel Doc XR (Bio-Rad).

Immunochemistry of tissue sections. Adult mice were perfused with saline and then $4 \%$ paraformaldehyde (PFA). Brains were harvested, postfixed in $4 \%$ PFA, dehydrated with $30 \%$ sucrose in PBS, and embedded into OCT. Ten to $20 \mu \mathrm{m}$ sagittal sections were processed for antigen retrieval using $10 \mathrm{~mm}$ sodium citrate, $\mathrm{pH} 7.1$, at $95^{\circ} \mathrm{C}$ for $20 \mathrm{~min}$ and cooled for $30 \mathrm{~min}$ [phosphorylated SMAD (p-SMAD), ID3 (inhibitor of differentiation or inhibitor of DNA binding), and SOX2, and dualthymidine experiments]. Sections were blocked with $10 \%$ goat serum for 1 h. Primary antibodies diluted in PBS containing 1\% BSA and $0.25 \%$ Triton X-100 were applied overnight at $4^{\circ} \mathrm{C}$. Antibodies used include BrdU (mouse IgG2a, 1:1000; Millipore), CldU (rat monoclonal antiBrdU, 1:250; Accurate Chemical and Scientific), IdU (mouse IgG1 antiBrdU, 1:500; BD Biosciences), glial fibrillary acidic protein (GFAP) [mouse IgG1, 1:400 (Sigma); rabbit, 1:500 (DakoCytomation)], polysialylated neural cell adhesion molecule (PSA-NCAM) (mouse IgM, 1:500; Millipore), phospho-SMAD1/5/8 (rabbit, 1:100; Cell Signaling Technol- ogies), ID3 (rabbit, 1:100; Santa Cruz Biotechnologies), SOX2 (rabbit, 1:100; Millipore), Noggin (rat, $3 \mu \mathrm{m} / \mathrm{ml}$; Regeneron), and green fluorescent protein (GFP) (rabbit, 1:500; Invitrogen). Primary antibodies were visualized with appropriate mouse or rabbit Alexa-Fluor-350/488/594/ 647 secondary antibodies (Invitrogen). Nuclei were counterstained with Hoechst 33342 (Sigma). Negative staining controls lacked application of the primary antibodies. Sections stained for BrdU, CldU, and IdU were pretreated with $2 \mathrm{~N} \mathrm{HCl}$ for $30-45$ min and neutralized with Borax, $\mathrm{pH}$ 8.5 , for 10 min before blocking. Cells were visualized using confocal laser microscopy (LSM 510 META; Carl Zeiss) and counted as described previously (Bonaguidi et al., 2005).

Primary neurosphere cultures. Adult neurospheres were isolated according to published methodologies (Bull and Bartlett, 2005). Adult (2-4 months of age, three to four per group) male C57BL/6 mice were killed by cervical dislocation, and their brains were immediately removed. A 2-mm-thick coronal slice was cut between -0.70 and -2.70 $\mathrm{mm}$, relative to bregma, according to an adult mouse brain atlas (Paxinos and Franklin, 2001). Hippocampal and posterior SVZ (pSVZ) areas were dissected (see Fig. 1) from the caudal side and carefully trimmed of all white matter. Tissue samples were minced with scissors and enzymatically digested with $0.1 \%$ trypsin-EDTA (Sigma) for $7 \mathrm{~min}$ at $37^{\circ} \mathrm{C}$. The digestion was quenched with $0.014 \% \mathrm{w} / \mathrm{v}$ trypsin inhibitor (type I-S from soybean; Sigma) in HBSS. After centrifugation, the pellet was resuspended in $1 \mathrm{ml}$ of serum-free medium (SFM) and mechanically triturated until smooth. The cells were filtered through a $70 \mu \mathrm{m}$ cell sieve (BD Biosciences), centrifuged, and resuspended in $100 \mu \mathrm{l}$ of SFM, and viable cells were counted on a hemocytometer using trypan blue (Sigma). Hippocampal and pSVZ cells were plated at a density of $7000 \mathrm{cells} / \mathrm{cm}^{2}$ in non-vacuum-treated 24-well plates (BD Biosciences) with $1 \mathrm{ml}$ of SFM per well. SFM consisted of DMEM/F-12 medium, supplemented with $\mathrm{N} 2, \mathrm{~B} 27,100 \mathrm{U} / \mathrm{ml}$ penicillin/streptomycin, glutamine (all from Invitrogen), and $2 \mu \mathrm{g} / \mathrm{ml}$ heparin (Sigma). The following growth factors were also included: $20 \mathrm{ng} / \mathrm{ml}$ human recombinant epidermal growth factor (EGF), $10 \mathrm{ng} / \mathrm{ml}$ mouse recombinant FGF-2 (both from BD Biosciences), and, when denoted, $250 \mathrm{ng} / \mathrm{ml}$ Noggin (R \& D Systems). Primary hippocampal cells were incubated for $8 \mathrm{~d}$, and pSVZ cells for $7 \mathrm{~d}$, in humidified $5 \% \mathrm{CO}_{2}$ to permit primary neurosphere formation. The neurospheres were then counted and collected for either passaging or immunocytochemistry.

Neurosphere passaging and differentiation. Neurospheres were dissociated as described previously (Bonaguidi et al., 2005). Spheres were harvested after $4-5 \mathrm{~d}$, and cells were counted and plated for self-renewal at a density of $1 \times 10^{4}$ cells $/ \mathrm{cm}^{2}$ in SFM plus EGF, FGF, and when denoted Noggin. The cell number per sphere was calculated by dividing the cell number by sphere number. Secondary sphere formation was performed in 96-well plates as described previously (Bonaguidi et al., 2005). Spheres were plated for differentiation at passage 11. For passage 11 expansions, cells were plated at low density $\left(1 \times 10^{3}\right.$ cells $\left./ \mathrm{cm}^{2}\right)$ in EGF, FGF, and Noggin. Once cells had grown for $5 \mathrm{~d}$, spheres were plated in SFM (without heparin) onto poly-D-lysine (PDL)-coated $(20 \mu \mathrm{g} / \mathrm{ml}$ for $>1 \mathrm{~h}$; Sigma) coverslips within 24 -well culture plates and allowed to differentiate until flattened and adherent for 5-7 d in humidified 5\% $\mathrm{CO}_{2}$. This was achieved by plating with $1 \mathrm{ng} / \mathrm{ml} \mathrm{FGF}$ for the first day and removal of FGF thereafter. The differentiated neurospheres were then fixed with $4 \%$ formaldehyde (Sigma) in $0.1 \mathrm{M}$ PBS at room temperature for $15 \mathrm{~min}$. After washing with PBS, cells were double stained for the neuronal panneurofilament (rabbit IgG, 1:4; Zymed Laboratories) and the "astrocytic" marker GFAP with Hoechst counterstain or triple stained with the neuronal marker MAP2 (mouse IgG1, 1:200; Millipore), GFAP (rabbit IgG, 1:1000; DakoCytomation), and oligodendrocyte marker O4 (mouse IgM, 1:200; Millipore).

Single-cell clonal analysis. Passage 8 hippocampal neurospheres generated in the presence of Noggin were dissociated and sorted by flow cytometry on the basis of size and granularity at the density of 1 cell per well. Cells were collected in non-adherent 96-well plates containing growth media with or without Noggin (four plates each). Cultures were refed with growth factors (and Noggin if needed) every 3-4 $\mathrm{d}$ and assayed for neurosphere formation after $14 \mathrm{~d}$ in vitro. Cell clusters $>50 \mu \mathrm{m}$ in diameter were counted as neurospheres. To test self-renewal, individual neu- 
rospheres were picked using a microscope, dissociated, and plated in proliferation conditions including Noggin for several passages. To assess multipotentially, passage 11 individual clonally derived neurospheres were differentiated as intact spheres under conditions described above and processed for immunocytochemistry of lineage markers as described.

Immunochemistry of primary hippocampal neurospheres. Primary neurospheres were processed in suspension. Spheres were fixed with $4 \%$ formaldehyde in PBS for $30 \mathrm{~min}$ at room temperature and blocked with $10 \%$ goat serum for $1 \mathrm{~h}$, and primary antibodies were applied overnight at $4^{\circ} \mathrm{C}$. Primary antibodies were visualized using Alexa-350, -488 , and -594 secondary antibodies (Invitrogen) applied for $5 \mathrm{~h}$ at room temperature. Adherent cultures were processed, and all images were acquired as described previously (Bonaguidi et al., 2005). Primary antibodies were used at the same concentrations as described above.

Morphometric and statistical evaluation. p-SMAD and ID3 quantization was performed using MetaMorph software version 6.3r5 (Molecular Devices). In vivo, confocal z-stacks $(0.8 \mu \mathrm{m}$ optical sections of $10 \mu \mathrm{m}$ tissue) acquired at $100 \times$ were flattened into $2.5 \mu \mathrm{m}$ optical sections using LSM 510 Image Examiner (Carl Zeiss) and imported into MetaMorph. Individual cells were picked in random, traced in the GCL and SGZ, and measured for signal intensity. Average intensity in GCL cells was normalized to 1 . In vitro, $1 \mu \mathrm{m}$ optical sections were acquired through whole neurospheres and imported into MetaMorph. For in vivo proliferation studies, Hoechst, BrdU, GFAP, and PSA-NCAM were acquired using four-channel confocal microscopy. GFAP and PSA-NCAM were pseudocolored red for easier visualization using Image Examiner software. All images were imported into Photoshop CS (Adobe Systems) to prepare figures. Statistical evaluations for two-group tests (unpaired, two-tailed, Student's $t$ test) and three-group (ANOVA, with Bonferroni's post hoc test) were performed using Prism software (GraphPad Software).

\section{Results \\ Noggin allows for self-renewal and multipotential differentiation of hippocampal cells}

Adult neural precursors proliferate in vitro in the presence of EGF and/or FGF to form floating cell clusters termed neurospheres (Reynolds and Weiss, 1992; Morshead et al., 1994; Gritti et al., 1996). NSCs are distinguishable from NPCs by the ability to selfrenew, i.e., expand continually (Bull and Bartlett, 2005). GFAPexpressing cells from the anterior and posterior SVZ, but not the hippocampus, give rise to neurospheres that continually expand (Gritti et al., 1999; Bull and Bartlett, 2005). We prepared adult EGF and FGF-responsive neurosphere cultures to investigate the effects of BMP inhibition on hippocampal and pSVZ cell selfrenewal. Cells were isolated from the dorsal part of the hippocampus (Hip) or the lateral wall of the lateral ventricle (pSVZ) and cultured through multiple passages (Fig. $1 F$ ). As reported previously (Bull and Bartlett, 2005), neurospheres isolated from the hippocampus failed to expand when cultured in EGF and FGF alone (Fig. $1 A, C$ ). However, Noggin addition allowed hippocampal cultures to expand for 10 passages, the longest time studied, with more than a 1000-fold increase in cell number (Fig. $1 A, D)$. SVZ-derived neurospheres cultured without Noggin expanded seven times faster than Noggin-treated hippocampal neurospheres (pSVZ, 16.9 × hippocampus, $2.35 \times$ ), but Noggin addition to $\mathrm{pSVZ}$ cultures did not further increase the expansion in cell numbers (Fig. $1 B$ ).

Neural stem cells possess the ability to self-renew and generate both neurons and glia. However, adult hippocampal stem/progenitor cells cultured in the presence of EGF and FGF alone predominately generate only glia, and inclusion of additional factors such as BDNF is necessary to facilitate neuronal differentiation in vitro (Seaberg and van der Kooy, 2002; Bull and Bartlett, 2005). Because we found that endogenous BMP signaling is responsible
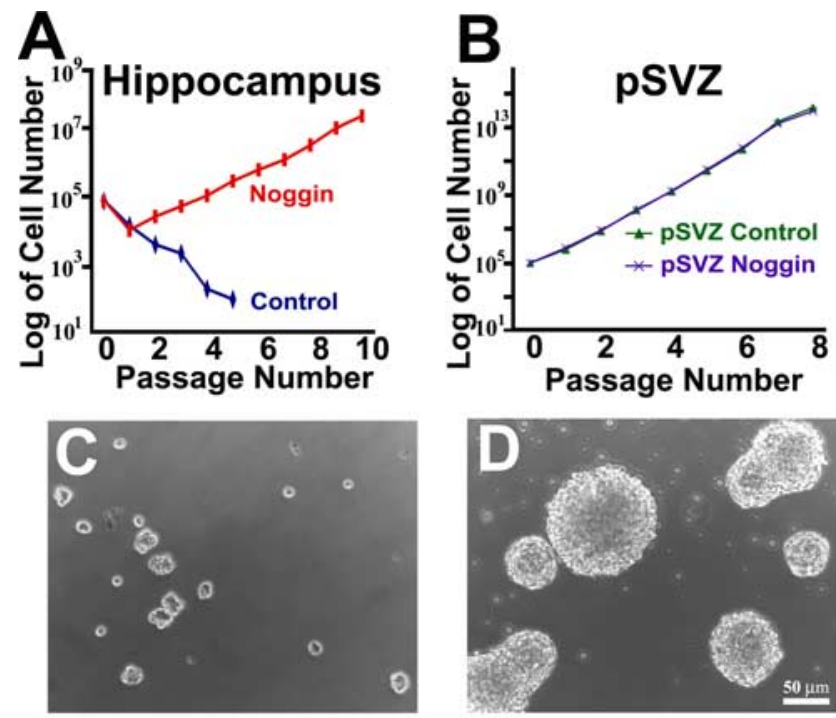

Passage 4 without Noggin

Passage 4 with Noggin
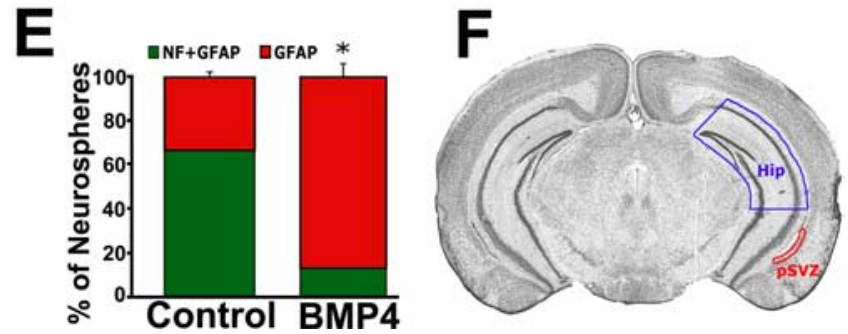

Figure 1. Noggin allows for hippocampal cell self-renewal and multipotential differentiation. $\boldsymbol{F}$, Coronal sections, $2 \mathrm{~mm}$ thick, were prepared from adult brain and placed caudal side up. The dorsal hippocampus (Hip) was isolated followed by the pSVZ region. $\boldsymbol{A}, \boldsymbol{C}$, Neurosphere cultures derived from the hippocampus fail to expand cell numbers in the presence of EGF and FGF through multiple passaging. $\boldsymbol{A}, \boldsymbol{D}$, Hippocampal cultures grown with Noggin addition expand for over 10 passages. $\boldsymbol{B}$, Neurospheres derived from $\mathrm{pSVZ}$ expand at a faster rate than do hippocampal neurospheres with Noggin addition. Noggin addition to pSVZ cultures does not affect expansion cell numbers. $\boldsymbol{E}$, Passage 11 hippocampal spheres expanded in Noggin were plated for differentiation with or without BMP addition. The number of spheres possessing both neurons [pan-neurofilament (NF) immunofluorescence] and glia (GFAP immunofluorescence) or glia only was counted. Whereas most neurospheres expanded with Noggin generate both neurons and glia, BMP addition during differentiation inhibits neuronal differentiation and promotes more glia-only spheres. Error bars in $E$ represent mean \pm SEM of three experiments. ${ }^{*} p=0.01$ by unpaired Student's $t$ test. $\boldsymbol{A}-\boldsymbol{D}$, Hippocampus (Hip; $\left.n=4\right) ; \operatorname{pSVZ}(n=4)$. $\boldsymbol{F}$ is modified from Paxinos and Franklin (2001), with permission.

for limiting self-renewal by cultured adult hippocampal precursors, we asked whether it is also responsible for limiting neuronal lineage commitment. After 10 passages in the presence of Noggin, hippocampal neurospheres were differentiated as intact spheres for $5-7 \mathrm{~d}$. The majority of neurospheres contained both neurons (neurofilament-immunoreactive cells) and astrocytes (GFAPimmunoreactive cells with mature morphology and loss of precursor characteristics) (Bonaguidi et al., 2005) (67 $\pm 5 \%$ ) (Fig. $1 E)$. Furthermore, addition of BMP4 during differentiation significantly reduced neuronal differentiation $(13 \pm 3 \% ; p=0.010)$ (Fig. 1E).

To address the multi-lineage potential of these putative hippocampal NSCs in more detail, we asked whether clonally derived neurospheres from a single cell are capable of generating cell types of all three neural lineages. Dissociated passage 8 hippocampal neurospheres maintained in the presence of Noggin were sorted by flow cytometry at one cell per well density into 96-well plates (Fig. 2A, arrow) and cultured with or without 


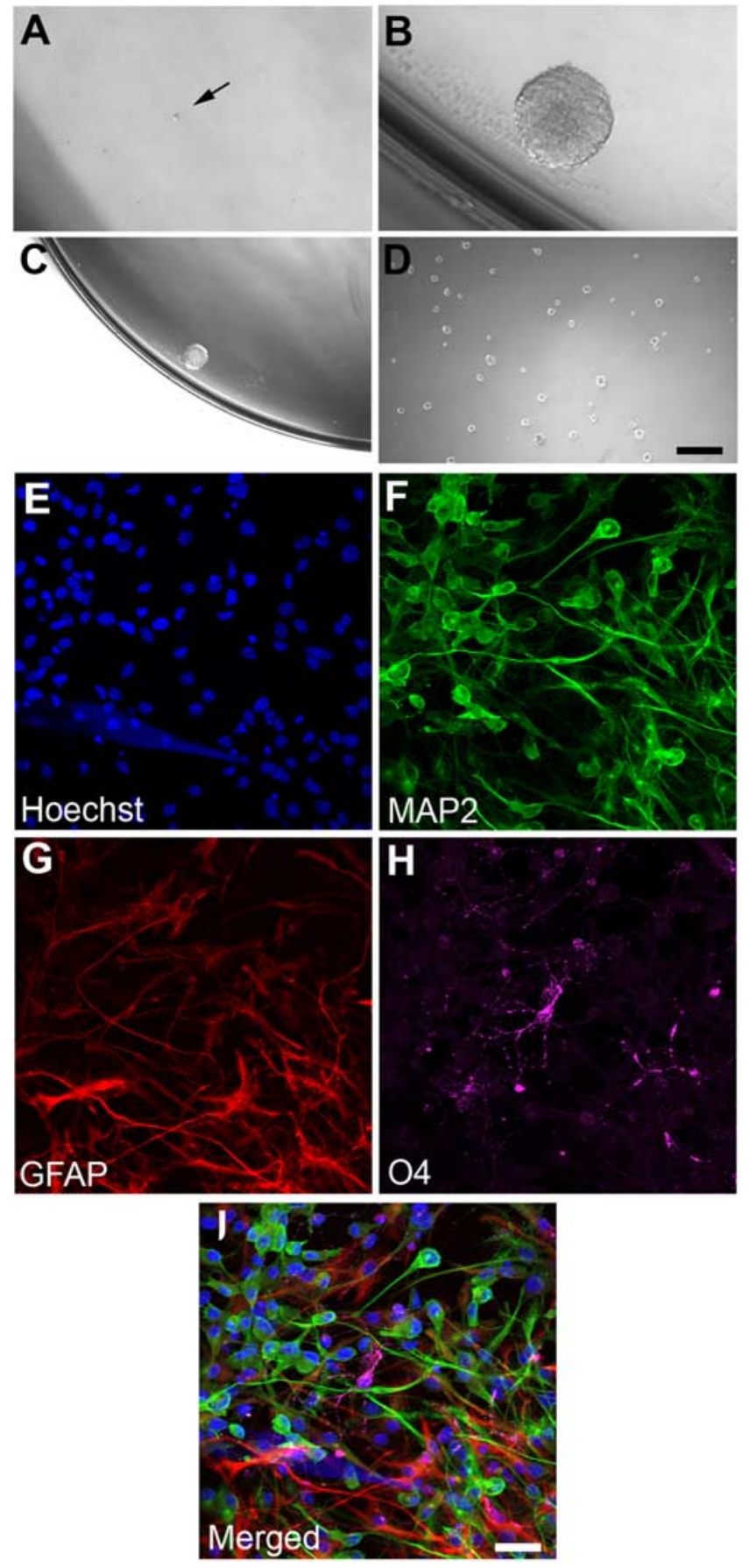

Figure 2. Single-cell derived, Noggin-promoted hippocampal progenitor gives rise to multiple neural lineages. $A$, Representative single cell (arrow) after sorting by flow cytometry based on size and granularity. $\boldsymbol{B}$, Representative neurosphere cultured in the presence of Noggin after $14 \mathrm{~d}$. Only cell clusters $>50 \mu \mathrm{m}$ were considered as neurospheres. $C, D$, Expansion of a Noggininduced neurosphere. $\boldsymbol{C}$, Single neurosphere after $14 \mathrm{~d}$ before dissociation; $\boldsymbol{D}$, additional neurospheres were observed $3 \mathrm{~d}$ after the second passage. Percentages of single cell clones that form neurospheres are higher in the presence of Noggin (4.43\%) compared with Noggin withdrawal $(0.26 \%) . E-I$, A single clonally derived neurosphere is capable of generating MAP2 ${ }^{+}$ neurons $(\boldsymbol{F}), \mathrm{GFAP}^{+}$astrocytes $(\boldsymbol{G})$, and $04^{+}$oligodendrocytes $(\boldsymbol{H})$ after $7 \mathrm{~d}$ in vitro under differentiation conditions. Scale bars: $\boldsymbol{A}, \boldsymbol{B}, 50 \mu \mathrm{m} ; \boldsymbol{C}, \boldsymbol{D}, 200 \mu \mathrm{m} ; \boldsymbol{E}-\mathbf{I}, 25 \mu \mathrm{m}$.

Noggin for $14 \mathrm{~d}$. For quantification, cell clusters $>50 \mu \mathrm{m}$ in diameter were counted as neurospheres (Fig. $2 B, C$ ). Interestingly, we found that, even after extended passages in vitro, hippocampal neurosphere formation remained dependent on Noggin, because the percentage of sphere-forming clones was greater with Noggin than without (4.23 vs $0.26 \%$ ). Additionally, singlecell-derived neurospheres were able to expand in cell number throughout subsequent passages (Fig. 2D), suggesting that these spheres possess the ability to self-renew. More importantly, differentiation of clonally derived neurospheres as intact spheres on PDL-coated coverslips produced all three neural lineage cell types: neurons (Fig. 2F,I), astrocytes (Fig. 2G,I), and oligodendrocytes (Fig. $2 \mathrm{H}, \mathrm{I}$ ). These findings provide additional evidence that the Noggin-promoted cell types in neurosphere-forming conditions exhibit neural stem cell characteristics.

To further define effects of BMP signaling on self-renewal and expansion, we counted the number of spheres as well as the number of cells in each sphere. Noggin addition to primary hippocampal neurospheres had no effect on either the number of spheres that formed $(0.04 \pm 0.01$ vs $0.05 \pm 0.02 \%)$ (Fig. $3 A)$ or the number of cells per sphere (206 \pm 72 vs $257 \pm 171$ ) (Fig. 3B). However, addition of Noggin to secondary hippocampal neurospheres significantly increased both sphere number $(0.45 \pm 0.08$ vs $1.23 \pm 0.11 \% ; p=0.0072$ ) (Fig. $3 C$ ) and cells per sphere $(193 \pm 74$ vs $1135 \pm 269 ; p=0.025)$ (Fig. $3 D)$. In contrast, addition of Noggin to either primary or secondary pSVZ neurospheres had no effect on sphere number or on the number of cells per sphere (Fig. 3).

In addition to the quantification of primary and secondary neurosphere cell numbers, we next examined the effect of Noggin on the cell cycle entry of hippocampal precursors. After $5 \mathrm{~d}$ with or without Noggin, hippocampal neurospheres were dissociated and labeled with the thymadine analog EdU for $4 \mathrm{~h}$. The percentage of EdU-labeled cells were subsequently analyzed by fluorescent-activated cell sorting (FACS). We found that cells grown in the presence of Noggin contained higher percentages of EdU labeling $(24.20 \pm 2.58 \%)$ compared with cells lacking Noggin exposure (9.90 $\pm 0.16 \% ; p=0.029)$ (Fig. $3 E)$, suggesting that inhibition of BMP signaling promotes proliferation of hippocampal NSCs. The maintenance of proliferative precursors is also supported by the expression of TERT in the Noggin promoted hippocampal neurospheres (Fig. 3F). TERT is an essential component of telomerase activity, a well established hallmark of stem cells that is also expressed by neural precursors (Meeker and Coffey, 1997; Cai et al., 2002; Caporaso et al., 2003). We found the level of TERT in Noggin-induced neurospheres was comparable with that found in the embryonic stem (ES) cell control, but we failed to detect TERT expression in hippocampal precursors grown without Noggin under the same experimental conditions. These findings indicate that BMP inhibition promotes selfrenewal, proliferation, and multipotential differentiation of adult hippocampal precursor cells in vitro but does not alter selfrenewal or expansion of cultured adult pSVZ precursor cells.

\section{Precursors in hippocampal, but not pSVZ, neurospheres possess BMP signaling in vitro}

During BMP signaling, SMAD1, SMAD5, and SMAD8 are phosphorylated and translocate with SMAD4 to the nucleus. SMAD proteins act as transcription factors in the nucleus and also induce the synthesis of ID proteins 1-4. Therefore, the presence of phosphorylated SMAD1/5/8 in the nucleus (np-SMAD) or induction of ID proteins are indicators of BMP signaling within a cell and act as key molecules in regulating biological responses to BMPs (Miyazono and Miyazawa, 2002). First, we examined the cellular localization of p-SMAD in primary hippocampal and SVZ neurospheres to determine whether endogenous BMP signaling occurs in the cultured cells. Hippocampal neurospheres had strong np-SMAD staining in most cells, which was reduced 
by culturing in the presence of Noggin $(88.2 \pm 2.2$ vs $31.5 \pm 3.6 \% ; p=0.0005)$ (Fig. $4 A, B$ ). In contrast, neurospheres from the pSVZ had np-SMAD staining in only a few cells $(3.5 \pm 0.8 \% ; p=0.0005)$ (Fig. $4 C$ ), and the staining was observed predominantly in the cytoplasm rather than the nucleus (Fig. 4D). Next, we performed immunocytochemistry to investigate levels of ID3 staining in primary hippocampal and SVZ neurospheres. Similar to p-SMAD observations, ID3 staining was dramatically lower in primary neurospheres from the SVZ compared with hippocampal neurospheres $(1.00 \pm 0.03$ vs $0.28 \pm 0.07 ; p=0.0002$ ) (Fig. $4 F, G$ ). Therefore, BMP signaling seems to occur primarily in adult hippocampal precursors but not adult pSVZ precursors in vitro.

\section{Noggin inhibits BMP signaling in SGZ precursor cells in vivo to amplify their numbers}

We next determined whether Noggin is expressed in the SGZ in vivo using immunocytochemistry (Fig. 5) (supplemental Fig. 1, available at www.jneurosci.org as supplemental material). We observed that Noggin is expressed in the GCL, SGZ, and hilus, indicating that it is appropriately localized to be involved in regulation of hippocampal neurogenesis (Fig. $5 A-C$ ) as has been reported previously at the RNA level (Fan et al., 2003; Chmielnicki et al., 2004). Neurogenesis in the adult SGZ originates from GFAP-expressing multipotential precursor cells in the SGZ and SVZ (Doetsch et al., 1997, 1999; Seri et al., 2001; Garcia et al., 2004). Activation of relatively quiescent $\mathrm{GFAP}^{+}$precursors gives rise to a rapidly dividing progenitor pool (transient amplifying progenitors). Amplifying progenitors commit to PSA-NCAM ${ }^{+}$migratory precursors that differentiate into immature neurons, mature in the GCL, and integrate into the hippocampus circuitry (for review, see Ma et al., 2005; Ming and Song, 2005). We next sought to determine the relationship between proliferation and BMP signaling in the SGZ by examining BrdU incorporation and its relationship to (1) np-SMAD staining and (2) BMP signaling target gene (ID3). BrdU-negative $\left(\mathrm{BrdU}^{-}\right)$cells in the GCL display strong np-SMAD staining, whereas $\mathrm{BrdU}^{+}$cells, and specifically $\mathrm{BrdU}^{+} \mathrm{GFAP}^{+}$cells, demonstrate reduced np-SMAD $\left(\mathrm{BrdU}^{-}, 1.00 \pm 0.02 ; \mathrm{BrdU}^{+}, 0.71 \pm 0.01 ; \mathrm{BrdU}^{+} \mathrm{GFAP}^{+}\right.$, $0.58 \pm 0.04 ; p=0.009$ ) (Fig. $5 D-H$ ). Furthermore, ID3 is only expressed in a small population of $\mathrm{BrdU}^{+}$cells in the SGZ $(22.1 \pm 1.0 \%)$ (Fig. $5 I-K)$. Thus, reduced BMP signaling is associated with proliferation in the hippocampal DG in vivo.

We then examined whether altering levels of Noggin expression influence hippocampal neurogenesis. To alter levels of Noggin expression, we used transgenic mice in which the neuronspecific enolase promoter drives expression of Noggin and a GFP cassette (NSE-Noggin) (Guha et al., 2004; Bonaguidi et al., 2005). Transgene expression begins in the hippocampus of these ani- mals when the GCL differentiates during postnatal development and continues into adulthood (Guha et al., 2004; Bonaguidi et al., 2005; Li and Pleasure, 2005). In addition, when cells in the granule cell layer overexpress Noggin, Noggin seems to be secreted unidirectionally toward the hilus to regulate precursors in the SGZ (supplemental Fig. 1, available at www.jneurosci.org as supplemental material). We next sought to confirm that BMP signaling is altered in SGZ precursors by assessing ID3 expression in NSE-Noggin, wild-type, and NSE-BMP4 overexpression mice. Compared with wild-type animals, the percentage of $\mathrm{BrdU}^{+}$cells that expressed ID3 were significantly decreased in Noggin animals $(22.1 \pm 1.0$ vs $11.5 \pm 0.6 \% ; p=0.0026)$ and increased in BMP4 animals $(22.1 \pm 1.0$ vs $40.2 \pm 3.0 \%$; $p=0.0026)$ (Fig. $5 I-K)$. Therefore, adult SGZ precursors respond to changes in BMP levels as assessed by ID3 within our transgenic system.

To specifically test whether the level of BMP signaling determines the rate of cell proliferation in the adult SGZ precursor populations, we examined BrdU incorporation in the NSE-Noggin mice. This approach allowed examination of proliferation of the major SGZ precursor populations: $\mathrm{GFAP}^{+}$precursors-puta- 

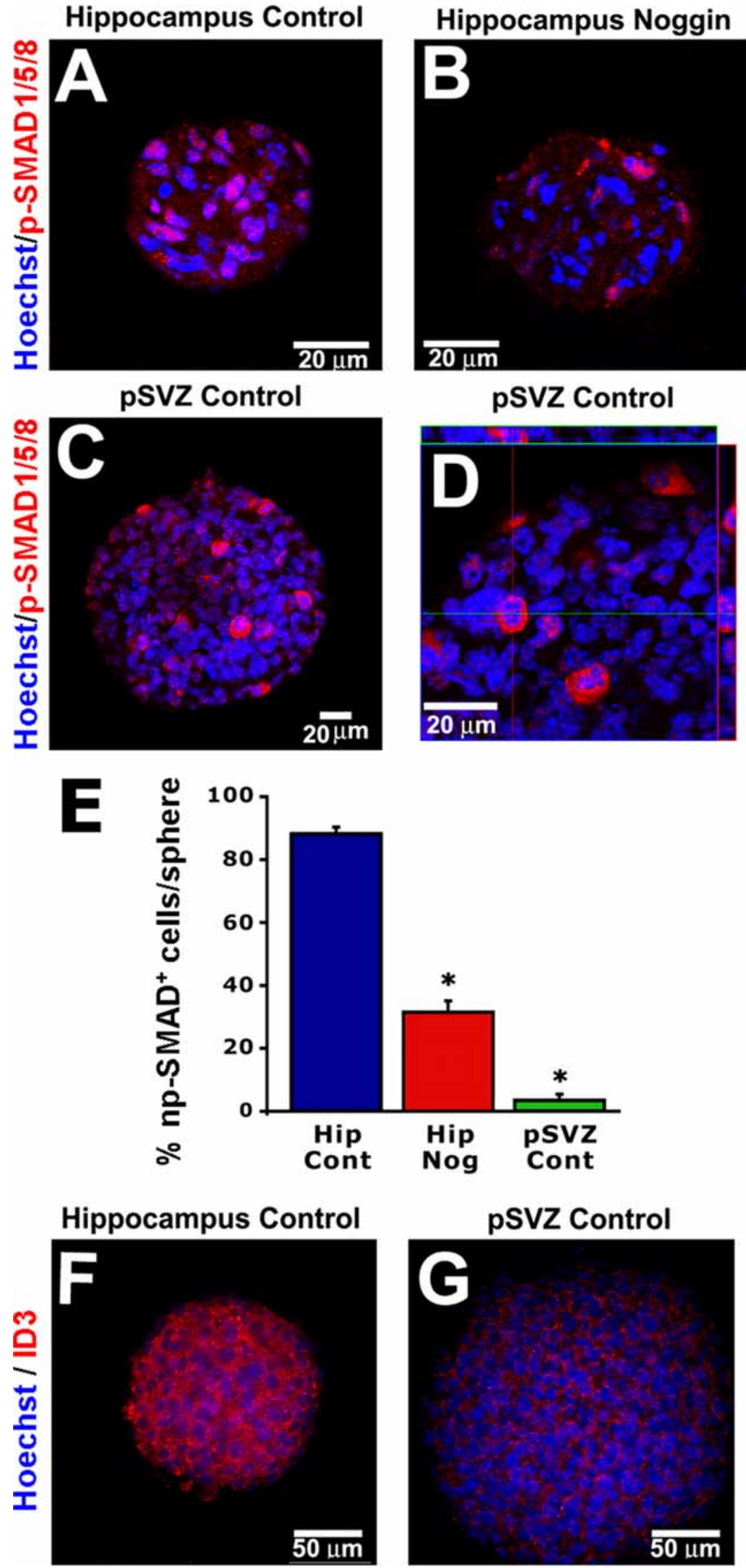

Figure 4. Strong BMP signaling occurs in hippocampal progenitors, but not pSVZ progenitors, in vitro. $A$, Primary hippocampal neurospheres grown in EGF and FGF for $8 \mathrm{~d}$ exhibit prominent np-SMAD1/5/8. $\boldsymbol{B}$, Noggin addition reduces np-SMAD staining in hippocampal neurospheres. C, pSVZ primary neurospheres do not display strong np-SMAD staining. $\boldsymbol{D}$, pSVZ spheres do have tive stem cells $\left(\mathrm{BrdU}^{+} \mathrm{GFAP}^{+}\right)$, putative transient amplifying cells $\left(\mathrm{BrdU}^{+}\right.$, $\mathrm{GFAP}^{-}$, and PSA-NCAM ${ }^{-}$), and proliferative migratory precursors cells $\left(\mathrm{BrdU}^{+} \mathrm{PSA}^{-\mathrm{NCAM}^{+}}{ }^{+}\right.$) (Ming and Song, 2005). Noggin overexpression significantly increased the number of overall proliferative precursors (481 \pm 18 vs $778 \pm 61$ cells $/ \mathrm{mm}^{2} ; p=0.007$ ) (Fig. $6 A, B, E)$, proliferative $\mathrm{GFAP}^{+}$cells $(104 \pm$ 4 vs $229 \pm 28$ cells $/ \mathrm{mm}^{2} ; p=0.010$ ) (Fig. $6 A, B, E)$, proliferative putative transient amplifying progenitor cells $(271 \pm 12 \mathrm{vs}$ $381 \pm 15$ cells $/ \mathrm{mm}^{2} ; p=0.004$ ) (Fig. $6 A-$ $E)$, and proliferative migratory precursor cells $\left(107 \pm 6\right.$ vs $168 \pm 23$ cells $/ \mathrm{mm}^{2} ; p=$ 0.048) (Fig. 6C-E). This increase in the number of $\mathrm{BrdU}^{+}$cells in each precursor population could reflect either enhanced proliferation of each cell type or increased proliferation of the $\mathrm{GFAP}^{+}$population that then generated increased numbers of the other proliferative precursor pools. To distinguish between these two possibilities, we examined the proportion of proliferative cells in each precursor population. Noggin did not change the proportion of proliferative migratory precursors $(22.1 \pm$ 1.2 vs $23.1 \pm 0.8 \% ; p=0.382$ ) (Fig. $6 F$ ). However, the proliferative $\mathrm{GFAP}^{+}$cell fraction in the transgenic animals was significantly increased $(21.5 \pm 0.2$ vs $29.2 \pm$ $1.5 \% ; p=0.006$ ) (Fig. $6 F$ ) at the expense other precursor cells $(56.4 \pm 1.4$ vs $47.6 \pm$ $1.4 \% ; p=0.010$ ) (Fig. $6 F$ ). These results suggest that the effects of Noggin on proliferation in the SGZ occur primarily on the $\mathrm{GFAP}^{+}$putative stem cells that then, in turn, generate more proliferative precursor cells.

Noggin increases slowly dividing stemlike cell numbers in the SGZ

NSCs are considered to be a relatively quiescent cell population with long cell cycle duration. This property distinguishes stem cells from more proliferative precursor pools, including transient amplifying progenitors (Doetsch et al., 1999; Seri et al., 2001). NSCs may be isolated in situ according to their retention of exogenous

p-SMAD staining in the cytoplasm of some cells but not the nucleus as demonstrated by confocal orthogonal views. $\boldsymbol{E}$, Quantification of cell percentage per sphere that exhibit npSMAD. Hip, Hippocampus. F, G, Primary hippocampal neurospheres also have significantly higher staining intensity for the BMP target gene ID3 compared with pSVZ primary neurospheres $(1.00 \pm 0.03$ vs $0.28 \pm 0.07 ; p=0.0002)$. Error bars represent mean \pm SEM of multiple spheres. ${ }^{*} p<0.001$ by ANOVA with the Bonferroni's post hoc test. ${ }^{* *} p<0.0005$ by unpaired Student's $t$ test. 
thymidine analogs after long-term survival (Morshead et al., 1994, 1998). To confirm the presence of stem cells in the adult SGZ and investigate the role of Noggin on putative NSC number, we performed a dual thymidine analog experiment. Wild-type and NSE-Noggin mice were given the nucleoside analog IdU in their drinking water for 2 weeks as a first marker for replicating cells. After a period of 1 week in the absence of label, the animals were administered the second nucleoside analog CldU for an additional 2 weeks, followed again by the absence of label for 1 week (Fig. 7A). During the initial labeling period with IdU, both putative NSCs and proliferative progenitors will become labeled. During the 4 week period after IdU administration, this label becomes diluted in rapidly dividing cells. Two classes of cells could retain the label: slowly dividing NSCs or cells that have ceased to divide (by differentiation or cell death). To remove the latter possibility, CldU is administered as its incorporation is expected in all dividing cells, including putative NSCs. Animals were then killed 1 week after CldU to allow transient amplifying cells to migrate away from the SGZ, primarily into the GCL. This strategy allows the subset of long-term labelretaining cells with stem cells tendencies to be labeled a second time (Maslov et al., 2004; Bauer and Patterson, 2006).

We first tested the efficacy of the paradigm by performing control experiments. Animals administered IdU and CldU were processed singularly with the IdU (anti-BrdU; BD Biosciences) or CldU (anti-BrdU; Accurate Chemical and Scientific) antibodies and both appropriate secondary antibodies. The opposite channel was devoid of staining, demonstrating that we could distinguish between the two labeling periods. Also, $\mathrm{IdU}^{+}$cells were located farther within the GCL than CldU ${ }^{+}$cells, which is consistent with labeling two temporally distinct precursor populations (supplemental Fig. 2A-H, available at www. jneurosci.org as supplemental material). Next, we evaluated differentiated tissue for the absence of dual thymidine analog cells. In the adult, neural precursors in the SVZ migrate through the rostral migratory stream and differentiate in the olfactory bulb (OB). High numbers of $\mathrm{CldU}^{+}$or $\mathrm{IdU}^{+}$cells were present in the OB. However, we did not observe any cellular colocalization of CldU and IdU, confirming the absence of putative NSCs in the OB (supplemental Fig. $2 I-L$, available at www.jneurosci.org as supplemental material) (Ming and Song, 2005). We then investigated whether wild-type animals possessed long-term dual thymidine-labeled cells in the SGZ. Dual-labeled cells were clearly discernible from single-labeled cells in the SGZ
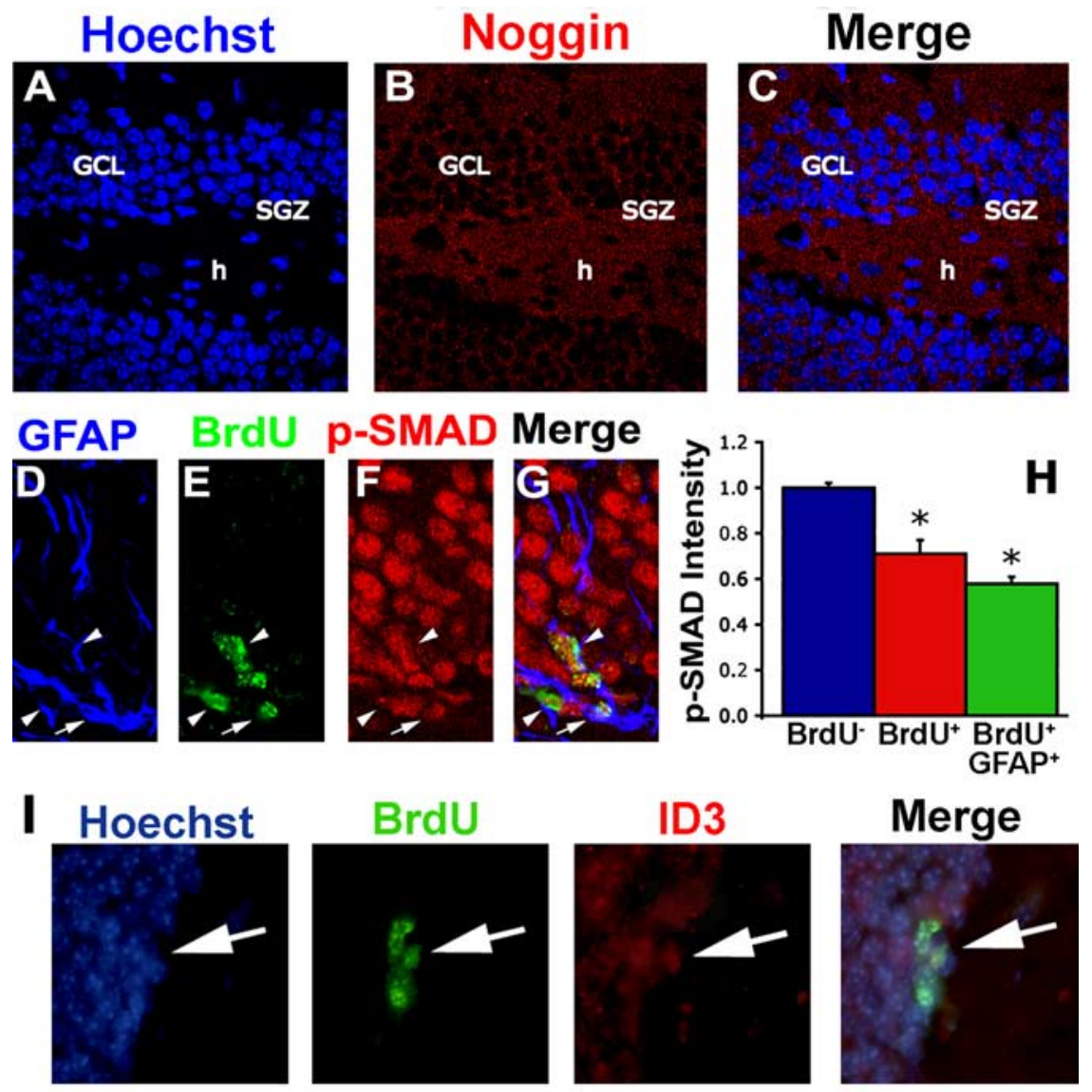

Merge
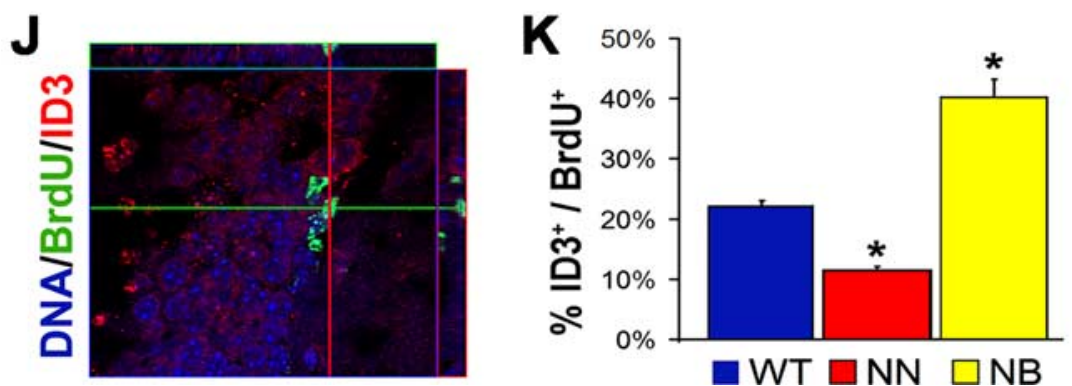

Figure 5. BMP signaling is present but essentially inhibited in SGZ precursor cells in vivo. $\boldsymbol{A}-\boldsymbol{C}$, Noggin protein is expressed in the $S G Z, G C L$, and hilus of the adult dentate gyrus. BMP signaling was assessed by immunofluorescence for the signal transducer p-SMAD1/5/8 (D-H) and target gene ID3 $(\boldsymbol{I}-\boldsymbol{K})$ in precursor cells labeled with BrdU for $3 \mathrm{~d}$. $\boldsymbol{D}-\boldsymbol{H}, \mathrm{Np}$-SMAD is decreased in proliferating cells in the SGZ and specifically within $\mathrm{GFAP}^{+} \mathrm{BrdU}^{+}$cells. Arrows point to BrdU ${ }^{+} \mathrm{GFAP}^{+}$cells, and arrowheads point to $\mathrm{BrdU}^{+} \mathrm{GFAP}^{-}$cells. I-K, ID3 reveals the presence of BMP signaling in some SGZ precursor cells (percentage of BrdU ${ }^{+}$ cells that coexpress ID3). J, Confocal orthogonal views demonstrate the colocalization of ID3 and BrdU. $\boldsymbol{K}$, The percentage of SGZ precursors that express ID3 increases in BMP overexpression (NSE-BMP4) animals and decreases in Noggin overexpression (NSE-Noggin) animals. Arrows point to ID3 ${ }^{+}$BrdU $^{+}$cells. h, Hilus; NN, NSE-Noggin; NB, NSE-BMP4. Error bars represent mean \pm SEM of at least 20 cells from three separate wild-type mice $(\boldsymbol{H})$ or three mice of each genotype $(\boldsymbol{K}) .{ }^{*}$ indicates difference from the $\mathrm{BrdU}^{-}$group at $p<0.01(\boldsymbol{H})$ or the wild-type group at $p<0.005(\boldsymbol{K})$ by ANOVA with the Bonferroni's post hoc test.
(Fig. $7 B$ ) and were quite low in number (17.7 \pm 3.4 CldU ${ }^{+} \mathrm{IdU}^{+}$cells $/ \mathrm{mm}^{2}$ ). In addition, some double-labeled cells colocalized with precursor makers SOX2 and GFAP, which confirms precursor identity of dual thymidine labelretaining cells (M. A. Bonaguidi, unpublished observations). Finally, we assessed the numbers of $\mathrm{CldU}^{+} \mathrm{IdU}^{+}$cells in the NSE-Noggin animals. Noggin overexpression significantly increased the number of label-retaining cells in the SGZ compared with wild-type controls $(29.7 \pm 2.1 \%$; $p=0.040)$. Thus, this study suggests that neural stem cells are present in the SGZ and their numbers are expanded by Noggin overexpression. 

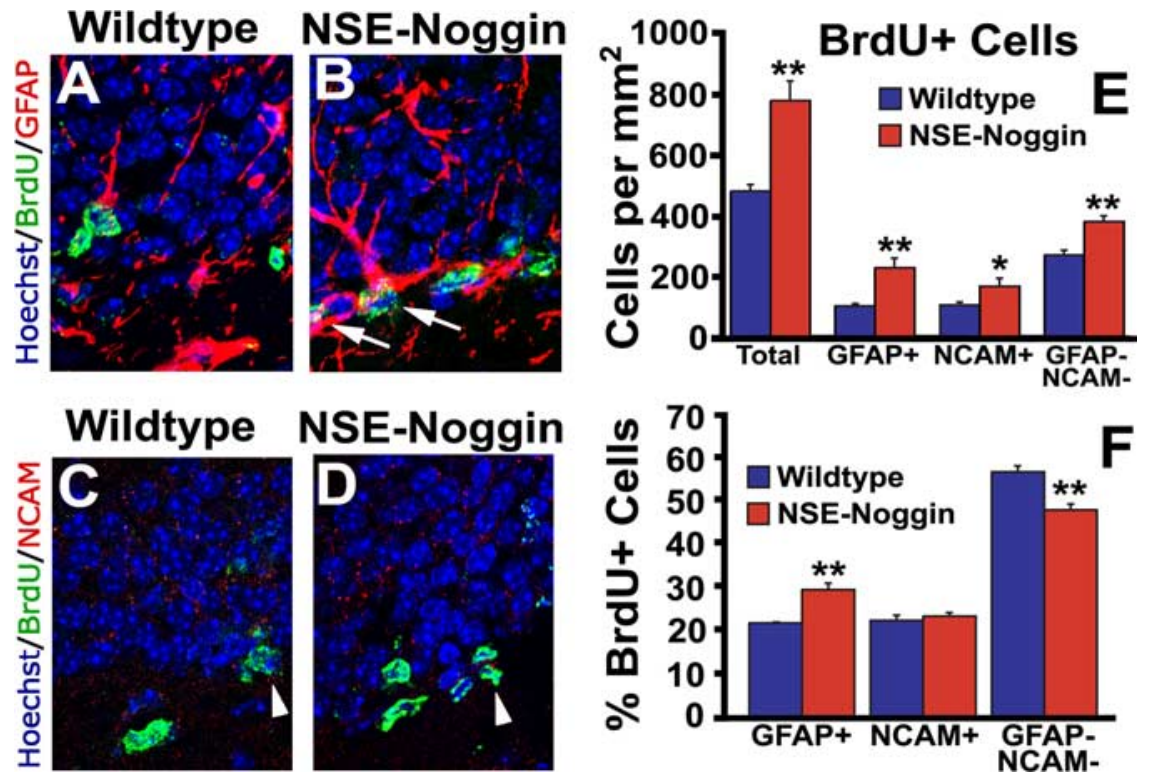

Figure 6. Noggin increases stem/progenitor cell proliferation. Noggin was overexpressed under the control of the NSE promoter. $\boldsymbol{A}-\boldsymbol{E}$, BrdU labeling and immunofluorescence reveals an increase in multiple precursor populations: GFAP ${ }^{+}$putative stem cells, PSA-NCAM ${ }^{+}$migratory precursors, and GFAP- PSA-NCAM ${ }^{-}$putative transient amplifying progenitors. $\boldsymbol{F}$, Although all three precursor populations are expanded, the proportion of GFAP ${ }^{+}$putative stem cells is increased at the expense of other precursors. Arrows point to GFAP ${ }^{+}$BrdU $^{+}$cells, and arrowheads point to PSA-NCAM ${ }^{+}$BrdU $^{+}$cells. NCAM, PSA-NCAM. Errorbars represent mean \pm SEM of three experiments. ${ }^{*} p<0.05 ;{ }^{* *} p \leq 0.01$ by unpaired Student's $t$ test.
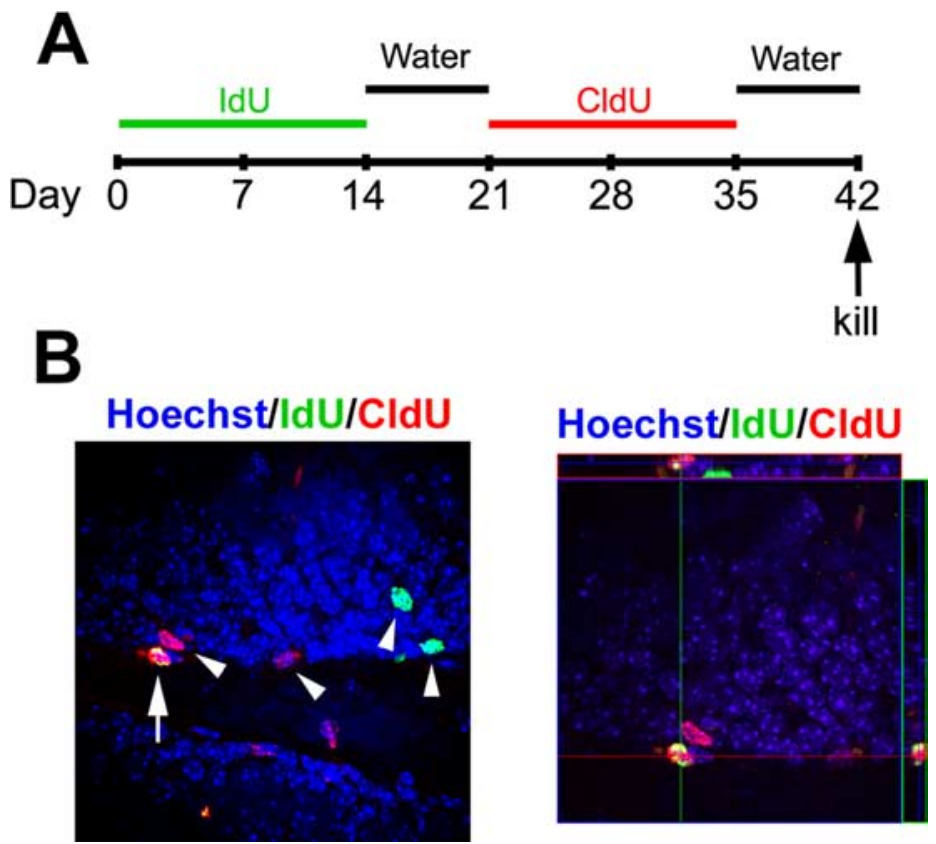

Figure 7. Noggin increases relatively quiescent stem cell numbers in the SGZ. A, Adult wild-type and NSE-Noggin mice were administered two thymidine analogs orally for $14 \mathrm{~d}$ each and regular drinking water for $7 \mathrm{~d}$ after each analog before the animals were killed. $\boldsymbol{B}$, Putative quiescent stem cells (IdU ${ }^{+} \mathrm{CldU}^{+}$; arrows) are distinguishable from more committed progeny $\left(\mathrm{IdU}^{+} \mathrm{CldU}^{-}\right.$or IdU ${ }^{-} \mathrm{CldU}^{+}$; arrowheads) in the SGZ. Noggin overexpression significantly increased the number of labelretaining cells in the SGZ $\left(29.7 \pm 2.1 \% \mathrm{CldU}^{+} \mathrm{IdU}^{+}\right.$cells $\left./ \mathrm{mm}^{2} ; p=0.040\right)$ compared with wild-type controls $(17.7 \pm 3.4$ CldU ${ }^{+} \mathrm{IdU}{ }^{+}$cells $\left./ \mathrm{mm}^{2}\right)$.

\section{Discussion}

This work provides in vitro and in vivo evidence that the adult hippocampus contains NSCs, which may be revealed through BMP inhibition. In single-cell and low-density cultures, high levels of BMP signaling occur endogenously in neurospheres de- rived from hippocampal precursors. Inhibiting BMP signaling with Noggin is sufficient to foster long-term hippocampal cell self-renewal, increased proliferation, and multipotential differentiation. In the SGZ, BMP signaling in precursors is limited by Noggin production. Overexpression of Noggin expands the overall precursor pool by increasing NSC numbers, which were assessed as GFAP-expressing and relatively quiescent cell populations.

This study, in part, investigated whether a local stem cell or non-self renewing progenitor is the source of constitutive neurogenesis in the adult hippocampus. The uncertainty primarily originates from differences in methodologies for harvesting and growing precursors in vitro (summarized by Babu et al., 2007). Contentions have arisen from more recent studies using neurosphere cultures (Bull and Bartlett, 2005; Walker et al., 2008) that hippocampal monolayer preparations of previous studies (Gage et al., 1995; Palmer et al., 1997) may be contaminated by stem cells from the adjacent SVZ. Our findings directly recapitulate the finding by Bull and Bartlett (2005) that hippocampal precursors do not self-renew as neurospheres when cultured in EGF and FGF alone, and both studies support similar observations by Seaberg and van der Kooy (2002). However, the self-renewing cells that were revealed in our hippocampal cultures by Noggin treatment likely do not represent contamination with cells from the pSVZ because (1) hippocampal precursors and pSVZ precursors expand with different growth kinetics, (2) endogenous BMP signaling differs between the precursor populations (Figs. 1, 3), and (3) pSVZ precursors expand without the need for Noggin, whereas the hippocampal precursors required Noggin for expansion.

Likewise, another potential source of NSCs may have originated from subcortical white matter. Although surrounding white matter was carefully removed during our hippocampal dissection, we cannot claim with $100 \%$ certainty whether $\mathrm{NG} 2{ }^{+}$progenitors remain in our cultures. $\mathrm{NG}^{+}{ }^{+}$white matter oligodendrocyte progenitor cells (OPCs) form neurospheres and undergo multi-lineage differentiation in vitro (Belachew et al., 2003; Nunes et al., 2003; Aguirre et al., 2004). However, unlike our Noggin preparations, these $\mathrm{NG}^{+}$ cells lack long-term self-renewal and TERT expression (Figs. 1-3) (Nunes et al., 2003). Although it remains possible that noggin "reprograms" OPCs, previous studies have demonstrated that applying BMP4 or a functionblocking antibody against noggin actually increases OPC plasticity (Kondo and Raff, 2000; Hampton et al., 2007). Ultimately, we 
believe that SGZ cells, and not SVZ or OPC, were the origin of expanding neurospheres in our cultures. Meanwhile, a recent report found that cultured hippocampal but not pSVZ NSC expand in response to depolarization promoted by $\mathrm{KCl}$ addition (Walker et al., 2008). Therefore, although it remains to be determined whether the cultures from previous monolayer and later neurosphere studies have similar cell sources, means to distinguish between SVZ and hippocampal origin are becoming more prevalent. Nonetheless, this and other recent studies now conclude that the adult hippocampus contains NSC populations as revealed by long-term culture under modified conditions (Babu et al., 2007; Walker et al., 2008).

However, the in vivo identities of cells capable of undergoing long-term self-renewal in vitro or in vivo still require clarification because a few cell sources have been suggested. SVZ precursors tagged in vivo by a GFAP-promoter driven virus or transgene are capable of neurosphere formation and propagation. Meanwhile, GFAP-expressing cells are considered relatively quiescent, remain after removing rapidly dividing cells, and contribute to neurogenesis in vivo and in vitro (Doetsch et al., 1999; Seri et al., 2001; Garcia et al., 2004; Seri et al., 2004). Together, GFAP ${ }^{+}$ radial glia-like cells in the SVZ and SGZ have been postulated as one source of NSC. Recently, Nonradial SOX $2{ }^{+} \mathrm{GFAP}^{-}$nonquiescent cells were hypothesized as multipotent and self-renewing cells in the SGZ that give rise to the radial cells (Suh et al., 2007). To identify putative NSCs in vivo, we administered thymidine analogs for $14 \mathrm{~d}$ each with $7 \mathrm{~d}$ water after each exposure (Fig. 7). This additional exposure length allowed for further dilution of the analog acquired by rapidly dividing precursors in case the estimated cell cycle time for NSC in the SGZ is longer than those in the SVZ (Morshead et al., 1998). Interestingly, 50\% of duallabeled cells were positive for SOX2 and a smaller percentage for GFAP in wild-type and NSE-Noggin animals (Bonaguidi, unpublished observations). Because we did not have a tag to identify the morphology of $\mathrm{SOX}_{2}{ }^{+}$cells, we were unable to confirm whether SOX $2{ }^{+}$cells contain a radial process. Therefore, it seems plausible that the label-retaining cells are a heterogeneous population, which may contain subpopulations of the two aforementioned cells types and possibly other postulated (Aguirre et al., 2004; Yamashima et al., 2004) or unidentified ones. Once definitive markers of NSCs become available, NSC identity and relatively quiescence may be elucidated as has been demonstrated in other stem cell niches (Kiel et al., 2005).

This study also demonstrates that removal of adult hippocampal precursors from niche components alters their capacity to self-renew. Similarly, hematopoietic stem cells (HSCs) rapidly lose the ability to self-renew when placed in culture, and they do not regain it when they are subsequently used in reconstitution assays in vivo. However, isolation and direct cell transplantation of HSCs into lethally irradiated animal rebuilds the entire immune system of the first and subsequent hosts (Lemischka et al., 1986; Spangrude et al., 1988; Osawa et al., 1996). Thus, HSC culture conditions do not properly recapitulate the niche in which the cell normally resides and leads to loss of HSC potential. We show here that this is also relevant for studying precursors from the adult hippocampus. Precursors removed from their niche do not self-renew in vitro unless BMP signaling is inhibited (Figs. 1-3). Importantly, this inhibition must be continually maintained to allow repeated self-renewal; otherwise, the stem cell population is lost. This observation implicates BMP signaling as a crucial regulator of neurogenesis decline during hippocampal aging (Kuhn et al., 1996).

Additionally, cell fate choices are altered through removal from the niche. SGZ precursors in vivo preferentially commit to neurons instead of glia, but hippocampal precursors in vitro preferentially differentiate into astrocytes (Seaberg and van der Kooy, 2002; Bull and Bartlett, 2005; Lie et al., 2005). We established that endogenous BMP signaling is responsible, at least in part, for the bias of cultured hippocampal precursors toward astrocytic differentiation because Noggin addition enhanced neuronal lineage commitment (Figs. 1, 2). It is likely that critical niche components that promote neurogenesis and/or inhibit gliogenesis are missing within current NSC culture assays (Hagg, 2005; Ma et al., 2005). As the roles of extrinsic factors in regulating self-renewal, proliferation, fate commitment, and differentiation are elucidated, in vitro assays may better reflect their in vivo counterparts.

Furthermore, we demonstrate that BMP signaling is a key niche regulator of NSC in the adult hippocampus. BMP4 and Noggin are both expressed in the SGZ and GCL in vivo in a scattered non-uniform distribution (Fig. 5) (Fan et al., 2003). $\mathrm{BMPs}$ are produced by precursors themselves, which likely regulate proliferation in an autocrine/paracrine manner (Figs. 3, 4). However, BMP signaling in SGZ proliferative cells is reduced relative to nonproliferative cells in the GCL (Fig. 5). Noggin is produced by cells in the GCL and is in close juxtaposition to cells with different levels of BMP signaling, suggesting that the adult SGZ neurogenic niche occurs in focal locations as opposed to the entire GCL/hilus border. Because BMPs regulate proliferation, this hypothesis is reinforced by the observations that proliferative precursors are located in the SGZ as focal clusters even after a long ( 12 or $14 \mathrm{~d}$ ) period of daily BrdU exposure (Fig. 7) (Kempermann et al., 1998). Also, primarily nonproliferative areas of CA1 and CA3 have higher levels of np-SMAD1/5/8 than dentate (Bonaguidi, unpublished observations) (Colak et al., 2008). This suggests a model in which the generation of neuronal precursors that synthesize BMP4 locally in the SGZ increases to the point at which the effects of Noggin are negated and proliferation ceases. Such a feedback mechanism could provide a way of regulating neurogenesis by either increasing Noggin synthesis or decreasing BMP synthesis in response to environmental cues (K. T. Gobeske, unpublished observations).

The robust effects of Noggin overexpression in the hippocampus (this study and Bonaguidi et al., 2005) suggest that BMP signaling is a key regulator of neurogenesis intensity. BMP signaling regulates neural stem cell number, proliferation, and cell fate commitment in the adult dentate and SVZ (Figs. 6, 7) (Lim et al., 2000). It is therefore a good candidate for molecular interventions to define the functional roles of adult neurogenesis in the young and aged hippocampus. Because neurogenesis is correlated with hippocampus-dependent learning and may be involved in depression and epilepsy (Parent et al., 1997; Gould et al., 1999; Shors et al., 2001; van Praag et al., 2002; Santarelli et al., 2003; Raber et al., 2004), pharmacologic manipulation of BMP signaling in the dentate gyrus may potentially exert profound effects on hippocampal function and behavior.

\section{References}

Aguirre AA, Chittajallu R, Belachew S, Gallo V (2004) NG2-expressing cells in the subventricular zone are type C-like cells and contribute to interneuron generation in the postnatal hippocampus. J Cell Biol 165:575-589.

Altman J, Das GD (1965) Autoradiographic and histological evidence of postnatal hippocampal neurogenesis in rats. J Comp Neurol 124:319-335.

Babu H, Cheung G, Kettenmann H, Palmer TD, Kempermann G (2007) Enriched monolayer precursor cell cultures from micro-dissected adult 
mouse dentate gyrus yield functional granule cell-like neurons. PLoS ONE 2:e388.

Bauer S, Patterson PH (2006) Leukemia inhibitory factor promotes neural stem cell self-renewal in the adult brain. J Neurosci 26:12089-12099.

Belachew S, Chittajallu R, Aguirre AA, Yuan X, Kirby M, Anderson S, Gallo V (2003) Postnatal NG2 proteoglycan-expressing progenitor cells are intrinsically multipotent and generate functional neurons. J Cell Biol 161:169-186.

Bonaguidi MA, McGuire T, Hu M, Kan L, Samanta J, Kessler JA (2005) LIF and BMP signaling generate separate and discrete types of GFAPexpressing cells. Development 132:5503-5514.

Bull ND, Bartlett PF (2005) The adult mouse hippocampal progenitor is neurogenic but not a stem cell. J Neurosci 25:10815-10821.

Cai J, Wu Y, Mirua T, Pierce JL, Lucero MT, Albertine KH, Spangrude GJ, Rao MS (2002) Properties of a fetal multipotent neural stem cell (NEP cell). Dev Biol 251:221-240.

Cao L, Jiao X, Zuzga DS, Liu Y, Fong DM, Young D, During MJ (2004) VEGF links hippocampal activity with neurogenesis, learning and memory. Nat Genet 36:827-835.

Caporaso GL, Lim DA, Alvarez-Buylla A, Chao MV (2003) Telomerase activity in the subventricular zone of adult mice. Mol Cell Neurosci 23:693-702.

Chmielnicki E, Benraiss A, Economides AN, Goldman SA (2004) Adenovirally expressed noggin and brain-derived neurotrophic factor cooperate to induce new medium spiny neurons from resident progenitor cells in the adult striatal ventricular zone. J Neurosci 24:2133-2142.

Colak D, Mori T, Brill MS, Pfeifer A, Falk S, Deng C, Monteiro R, Mummery C, Sommer L, Götz M (2008) Adult neurogenesis requires Smad4mediated bone morphogenic protein signaling in stem cells. J Neurosci 28:434-446.

Derynck R, Zhang YE (2003) Smad-dependent and Smad-independent pathways in TGF-beta family signalling. Nature 425:577-584.

Doetsch F, García-Verdugo JM, Alvarez-Buylla A (1997) Cellular composition and three-dimensional organization of the subventricular germinal zone in the adult mammalian brain. J Neurosci 17:5046-5061.

Doetsch F, Caillé I, Lim DA, García-Verdugo JM, Alvarez-Buylla A (1999) Subventricular zone astrocytes are neural stem cells in the adult mammalian brain. Cell 97:703-716.

Fan X, Xu H, Cai W, Yang Z, Zhang J (2003) Spatial and temporal patterns of expression of Noggin and BMP4 in embryonic and postnatal rat hippocampus. Brain Res Dev Brain Res 146:51-58.

Gage FH, Coates PW, Palmer TD, Kuhn HG, Fisher LJ, Suhonen JO, Peterson DA, Suhr ST, Ray J (1995) Survival and differentiation of adult neuronal progenitor cells transplanted to the adult brain. Proc Natl Acad Sci U S A 92:11879-11883

Garcia AD, Doan NB, Imura T, Bush TG, Sofroniew MV (2004) GFAPexpressing progenitors are the principal source of constitutive neurogenesis in adult mouse forebrain. Nat Neurosci 7:1233-1241.

Gomes WA, Mehler MF, Kessler JA (2003) Transgenic overexpression of BMP4 increases astroglial and decreases oligodendroglial lineage commitment. Dev Biol 255:164-177.

Gould E, Beylin A, Tanapat P, Reeves A, Shors TJ (1999) Learning enhances adult neurogenesis in the hippocampal formation. Nat Neurosci 2:260-265.

Gritti A, Parati EA, Cova L, Frolichsthal P, Galli R, Wanke E, Faravelli L, Morassutti DJ, Roisen F, Nickel DD, Vescovi AL (1996) Multipotential stem cells from the adult mouse brain proliferate and self-renew in response to basic fibroblast growth factor. J Neurosci 16:1091-1100.

Gritti A, Frölichsthal-Schoeller P, Galli R, Parati EA, Cova L, Pagano SF, Bjornson CR, Vescovi AL (1999) Epidermal and fibroblast growth factors behave as mitogenic regulators for a single multipotent stem cell-like population from the subventricular region of the adult mouse forebrain. J Neurosci 19:3287-3297.

Guha U, Mecklenburg L, Cowin P, Kan L, O’Guin WM, D’Vizio D, Pestell RG, Paus R, Kessler JA (2004) Bone morphogenetic protein signaling regulates postnatal hair follicle differentiation and cycling. Am J Pathol 165:729-740.

Hagg T (2005) Molecular regulation of adult CNS neurogenesis: an integrated view. Trends Neurosci 28:589-595.

Hampton DW, Asher RA, Kondo T, Steeves JD, Ramer MS, Fawcett JW (2007) A potential role for bone morphogenetic protein signalling in glial cell fate determination following adult central nervous system injury in vivo. Eur J Neurosci 26:3024-3035.

Kaplan MS, Hinds JW (1977) Neurogenesis in the adult rat: electron microscopic analysis of light radioautographs. Science 197:1092-1094.

Kempermann G, Kuhn HG, Gage FH (1998) Experience-induced neurogenesis in the senescent dentate gyrus. J Neurosci 18:3206-3212.

Kiel MJ, Yilmaz OH, Iwashita T, Yilmaz OH, Terhorst C, Morrison SJ (2005) SLAM family receptors distinguish hematopoietic stem and progenitor cells and reveal endothelial niches for stem cells. Cell 121:1109-1121.

Kondo T, Raff M (2000) Oligodendrocyte precursor cells reprogrammed to become multipotential CNS stem cells. Science 289:1754-1757.

Kuhn HG, Dickinson-Anson H, Gage FH (1996) Neurogenesis in the dentate gyrus of the adult rat: age-related decrease of neuronal progenitor proliferation. J Neurosci 16:2027-2033.

Lemischka IR, Raulet DH, Mulligan RC (1986) Developmental potential and dynamic behavior of hematopoietic stem cells. Cell 45:917-927.

Li G, Pleasure SJ (2005) Morphogenesis of the dentate gyrus: what we are learning from mouse mutants. Dev Neurosci 27:93-99.

Lie DC, Colamarino SA, Song HJ, Désiré L, Mira H, Consiglio A, Lein ES, Jessberger S, Lansford H, Dearie AR, Gage FH (2005) Wnt signalling regulates adult hippocampal neurogenesis. Nature 437:1370-1375.

Lim DA, Tramontin AD, Trevejo JM, Herrera DG, García-Verdugo JM, Alvarez-Buylla A (2000) Noggin antagonizes BMP signaling to create a niche for adult neurogenesis. Neuron 28:713-726.

Ma DK, Ming GL, Song H (2005) Glial influences on neural stem cell development: cellular niches for adult neurogenesis. Curr Opin Neurobiol 15:514-520.

Maslov AY, Barone TA, Plunkett RJ, Pruitt SC (2004) Neural stem cell detection, characterization, and age-related changes in the subventricular zone of mice. J Neurosci 24:1726-1733.

Meeker AK, Coffey DS (1997) Telomerase: a promising marker of biological immortality of germ, stem, and cancer cells. A review. Biochemistry (Mosc) 62:1323-1331.

Ming GL, Song H (2005) Adult neurogenesis in the mammalian central nervous system. Annu Rev Neurosci 28:223-250.

Miyazono K, Miyazawa K (2002) Id: a target of BMP signaling. Sci STKE 2002:PE40.

Morshead CM, Reynolds BA, Craig CG, McBurney MW, Staines WA, Morassutti D, Weiss S, van der Kooy D (1994) Neural stem cells in the adult mammalian forebrain: a relatively quiescent subpopulation of subependymal cells. Neuron 13:1071-1082.

Morshead CM, Craig CG, van der Kooy D (1998) In vivo clonal analyses reveal the properties of endogenous neural stem cell proliferation in the adult mammalian forebrain. Development 125:2251-2261.

Nunes MC, Roy NS, Keyoung HM, Goodman RR, McKhann G 2nd, Jiang L, Kang J, Nedergaard M, Goldman SA (2003) Identification and isolation of multipotential neural progenitor cells from the subcortical white matter of the adult human brain. Nat Med 9:439-447.

Osawa M, Hanada K, Hamada H, Nakauchi H (1996) Long-term lymphohematopoietic reconstitution by a single CD34-low/negative hematopoietic stem cell. Science 273:242-245.

Palmer TD, Takahashi J, Gage FH (1997) The adult rat hippocampus contains primordial neural stem cells. Mol Cell Neurosci 8:389-404.

Parent JM, Yu TW, Leibowitz RT, Geschwind DH, Sloviter RS, Lowenstein DH (1997) Dentate granule cell neurogenesis is increased by seizures and contributes to aberrant network reorganization in the adult rat hippocampus. J Neurosci 17:3727-3738.

Paxinos G, Franklin KGJ (2001) The mouse brain in stereotaxic coordinates, Ed 2. San Diego: Academic.

Raber J, Rola R, LeFevour A, Morhardt D, Curley J, Mizumatsu S, VandenBerg SR, Fike JR (2004) Radiation-induced cognitive impairments are associated with changes in indicators of hippocampal neurogenesis. Radiat Res 162:39-47.

Reynolds BA, Weiss S (1992) Generation of neurons and astrocytes from isolated cells of the adult mammalian central nervous system. Science 255:1707-1710

Santarelli L, Saxe M, Gross C, Surget A, Battaglia F, Dulawa S, Weisstaub N, Lee J, Duman R, Arancio O, Belzung C, Hen R (2003) Requirement of hippocampal neurogenesis for the behavioral effects of antidepressants. Science 301:805-809.

Seaberg RM, van der Kooy D (2002) Adult rodent neurogenic regions: the 
ventricular subependyma contains neural stem cells, but the dentate gyrus contains restricted progenitors. J Neurosci 22:1784-1793.

Seri B, García-Verdugo JM, McEwen BS, Alvarez-Buylla A (2001) Astrocytes give rise to new neurons in the adult mammalian hippocampus. J Neurosci 21:7153-7160.

Seri B, García-Verdugo JM, Collado-Morente L, McEwen BS, Alvarez-Buylla A (2004) Cell types, lineage, and architecture of the germinal zone in the adult dentate gyrus. J Comp Neurol 478:359-378.

Shors TJ, Miesegaes G, Beylin A, Zhao M, Rydel T, Gould E (2001) Neurogenesis in the adult is involved in the formation of trace memories. Nature 410:372-376.

Spangrude GJ, Heimfeld S, Weissman IL (1988) Purification and characterization of mouse hematopoietic stem cells. Science 241:58-62.
Suh H, Consiglio A, Ray J, Sawai T, D’Amour KA, Gage FH (2007) In vivo fate analysis reveals the multipotent and self-renewal capacities of Sox $2(+)$ neural stem cells in the adult hippocampus. Cell Stem Cell 1:515-528.

van Praag H, Schinder AF, Christie BR, Toni N, Palmer TD, Gage FH (2002) Functional neurogenesis in the adult hippocampus. Nature 415:1030-1034.

Walker TL, White A, Black DM, Wallace RH, Sah P, Bartlett PF (2008) Latent stem and progenitor cells in the hippocampus are activated by neural excitation. J Neurosci 28:5240-5247.

Yamashima T, Tonchev AB, Vachkov IH, Popivanova BK, Seki T, Sawamoto $\mathrm{K}$, Okano H (2004) Vascular adventitia generates neuronal progenitors in the monkey hippocampus after ischemia. Hippocampus 14:861-875. 